\title{
CULTURA ESCOLAR NAS CLASSES EXPERIMENTAIS SECUNDÁRIAS DO COLÉGIO DAS CÔNEGAS DE SANTO AGOSTINHO PELAS MEMÓRIAS DA PROFESSORA ELZA MINÉ (1959-1962)
}

\author{
School culture in experimental secondary classes of the Cônegas de Santo \\ Agostinho School by the memories of the teacher Elza Miné (1959-1962)
}

Cultura escolar de las clases experimentales secundarias del Colégio de las Cônegas de Santo Agostino pelas memorias de la professora Elza Miné (1959-1962)

\author{
Fernanda Gomes Vieira* \\ Norberto Dallabrida*
}

\section{Resumo}

As classes secundárias experimentais renovaram, de forma significativa, o ensino secundário brasileiro nos anos 1950 e 1960. Na rede católica, esta experiência foi realizada a partir da apropriação da Pedagogia Personalizada e Comunitária (PPC), criada pelo padre jesuíta francês Pierre Faure, que aproxima a Escola Nova e a tradição educacional católica. Assim, o objetivo deste trabalho é compreender a cultura escolar na classe secundária experimental do Colégio das Cônegas de Santo Agostinho, de 1959 a 1962, educandário católico, elitista e destinado ao público feminino, a partir das memórias da ex-professora de latim e português Elza Assunção Miné. Como referencial teórico são utilizados os conceitos de cultura escolar, enunciado por Dominique Julia, e de apropriação, cunhado por Roger Chartier. A entrevista com a exprofessora Elza Miné foi feita nos moldes da metodologia da história oral, que considera a memória marcada pela subjetividade. Desta forma, na cultura escolar das classes secundárias experimentais do Colégio das Cônegas de Santo Agostinho, o foco foi colocado sobre as dimensões espaço-temporais flexíveis e o trabalho individual e colaborativo de pesquisa orientado por roteiros de estudo inscrito em fichas.

PALAVRAS-CHAVE: Cultura escolar. Classes Secundárias Experimentais. Pedagogia Personalizada e Comunitária

\begin{abstract}
The experimental secondary classes renewed in a meaningful way the Brazilian's secondary school in the 1950 and 1960 decades. In the Catholic's Schools, this experience has appropriated the Personalize and Community Pedagogy (PPC), created by the French Jesuit priest Pierre Faure, that brings closer the New School and the Catholic traditional education.

\footnotetext{
* Acadêmica do Curso de Pedagogia da Universidade do Estado de Santa Catarina (CEAD/UDESC), bolsista PIBIC/CNPq.

* Doutor em História Social pela Universidade de São Paulo (2001). Realizou estágio pós-doutoral na Universidad de Alcalá de Henares (2013) e atuou como professor visitante na Université Paris Nanterre (2019). Atualmente é professor concursado (efetivo) e pesquisador na Universidade do Estado de Santa Catarina (UDESC) e do CNPq. É professor de História da Educação no Curso de Pedagogia a Distância e docente vinculado ao Programa de Pós-Graduação em Educação na UDESC e líder do grupo de pesquisa Culturas Escolares, História e Tempo Presente.
} 
The purpose of this article is to comprehend the school culture in experimental secondary classes of the Cônegas de Santo Agostinho School, confessional and elitist school for girls, from 1959 to 1962 by the memories of the Latin and Portuguese teacher Elza Assunção Miné. To do so, we use concepts of school culture by Dominique Julia and appropriation by Roger Chartier. The interview with the ex-teacher Elza Miné was executed by the oral history's method, which considerate that memories are marked by subjectivity. Therefore, in the experimental secondary classes of Cônegas de Santo Agostinho School, the focus was the flexible school space and time dimensions and the individual and collaborative work guided by study scripts applied in sheets

KEYWORDS: School Culture. Experimental Secondary Classes. Personalize and Community Pedagogy

\section{Resumen}

Las clases experimentales secundarias renovaran de manera significativa la enseñanza secundaria brasileña en los años 1950 y 1960. En las escuelas católicas, esta experiencia fue realizada a partir de la apropiación de la Pedagogía Personalizada y Comunitaria (PPC), criada por él padre jesuita francés Pierre Faure, que aproxima la Escuela Nueva y la tradición educacional católica. Así, el objetivo del trabajo es comprender la cultura escolar en la clase secundaria experimental del Colegio de las Cônegas del Santo Agostino, de 1959 hasta 1962, confesional, elitista y destinado al público femenino, a partir de las memorias de la exprofesora de latín y portugués Elza Assunção Miné. Como referencial teórico son utilizados los conceptos de cultura escolar, hablado por Dominique Julia, y de apropiación, cunado por Roger Chartier. La entrevista con la exprofesora Elza Miné fue ejecutada en los moldes da metodología de la historia oral, que considera la memoria cargada por la subjetividad. De esta manera, en la cultura escolar de las clases secundarias experimentales del Colegío de las Cônegas del Santo Agostino, él foco fue puesto en las dimensiones espaciotemporales flexibles y él trabajo individual y colaborativo de la pesquisa orientado por los guiones de estudio inscrito en las fichas.

PALABRAS CLAVE: Cultura Escolar. Clases Secundarias Experimentales. Pedagogía Personalizada y Comunitaria

\section{INTRODUÇÃO}

A década de 1950 ficou marcada pelas experiências renovadoras nas escolas secundárias, tendo como base, principalmente, os modelos franceses. No sistema público, encontramos o pioneirismo de Luís Contier que, após estágio realizado no Centre International d'Études Pedagogiques (CIEP) em Sèvres, apropriou-se do modelo francês das classes nouvelles (classes novas) inovando no ensino secundário do Instituto Alberto Conte. Gildásio Amado, diretor da Diretoria do Ensino Secundário (DESE) articulou com o Ministério da Educação e Cultura a abertura e a legalização das classes experimentais (VIEIRA e CHIOZZINI, 2018). De maneira controlada pelo MEC foram propostas as instruções para a implantação das classes secundárias experimentais em 1958 (CUNHA e ABREU, 1963), que começam a ser implantadas em alguns estabelecimentos de ensino público e privado, no ano seguinte, principalmente em São Paulo, Rio de Janeiro e Rio Grande do Sul. 
O movimento na rede particular de ensino para a implantação das classes experimentais em 1959 ocorreu em sua grande parte nos educandários confessionais. A busca deles por manter o lugar de influência através da renovação teve como base a apropriação dos ensinamentos trazidos ao país pelo educador e padre jesuíta francês Pierre Faure, criador da Pedagogia Personalizada e Comunitária (PPC) que tem em si uma crestomatia da escola nova (DALLABRIDA, 2018). Faure inspirou-se em diversos autores, tanto clássicos como escolanovistas e católicos, mas a sua principal referência pedagógica foi Hélène Lubienska de Lenval, que realizou junto a ele trabalhos educativos. Faure integrou na sua proposta pedagógica as dimensões: personalista e comunitária, de sorte que "esta síntese personalista das orientações individualistas (Dalton, Winnetka) e socializantes (Cousinet, Kerschensteiner, Freinet) constitui a máxima contribuição de Faure no campo da pedagogia e da elaboração de certas técnicas" (DE GOMÉS, 1997, p.40). Assim, ele construiu uma pedagogia que desenvolvesse integralmente o indivíduo, contemplando a perspectiva católica.

A Pedagogia Personalizada e Comunitária pode ser resumida como o ensino autônomo pela pesquisa, baseado no uso das fichas que proporcionam um trabalho regular e organizado; a utilização personalizada do tempo; o espaço propício para a busca do alunado pela sua autonomia cognoscente; a partilha de conhecimentos e a avaliação conceitual. Além disso, Pierre Faure destaca a formação de valores morais e espirituais, influência da sua formação e da relação com o catolicismo social. Assim, no início de 1959, o educador católico ministrou, na cidade de São Paulo, um curso de formação docente, que difundiu a PPC para o ensino secundário, com o intuito de implantar as classes secundária, sendo estimulado pela Associação da Educação Católica (A.E.C). Os colégios envolvidos foram: Santa Cruz, Sion e das Cônegas de Santo Agostinho, pioneiros da experiência renovadora católica, que começou com os colégios afrancesados da burguesia paulista e depois atingiu o Rio de Janeiro e o Rio Grande do Sul (DALLABRIDA, 2018).

Assim, o presente trabalho procura estudar a cultura escolar das classes secundárias experimentais do Colégio das Cônegas de Santo Agostinho - popularmente conhecido como Des Oiseaux - educandário tradicional, elitista e direcionado ao público feminino e dirigido por freiras belgas de ascendência francesa. Trata-se da experiência renovadora nele implantada no período de 1959 a 1962, que compreende o primeiro ciclo do secundário, ou seja, o curso ginasial. Entende-se a escola como uma instituição educacional com poder e decisões próprias, que se encontra inserida em uma realidade social, material e cultural específica, em que esta atribui sentidos à questão do espaço e do tempo escolar (SCHEREIBER, 2016). O foco será colocado sobre as dimensões espaço-temporais e do ensino pela pesquisa como partes da cultura escolar das classes secundárias experimentais do Colégio das Cônegas de Santo Agostinho, que se diferenciavam da cultura institucionalizada.

A cultura escolar é compreendida como um conjunto de normas estabelecidas no intuito de delimitar conhecimentos e incitar comportamentos por práticas didáticas, que podem variar conforme a época por questões religiosas, sociopolíticas ou de civilização (JULIA, 2001). Para ler a questão da apropriação e ressignificação da Pedagogia Personalizada e Comunitária pelo Colégio das Cônegas de Santo Agostinho adota-se a visão do historiador francês Roger Chartier (1992), onde o ato de apropriar-se pouco se reduz ao desejo/intenção dos autores dos discursos e normas. Aqui entra a ideia de que a imposição não é puramente controlada e nem livre de ser influenciada pelo objeto que se quer ver influenciado; afinal, os bens culturais produzidos e circulados são recebidos 
dos mais diversos modos, ou seja, criativamente, que podem trazer resistências, ressignificações e reestruturações ao que foi prescrito (CHARTIER,1992). E assim temse a dialética de análise: cultura escolar prescrita pela PPC e praticada pelo Colégio Des Oiseaux.

Para alcançar estes objetivos, o trabalho estudará o Colégio das Cônegas de Santo Agostinho com base na entrevista conferida pela Elza Assunção Miné, que foi exaluna, interna, do ginásio e do colegial (clássico), cursou a faculdade de letras neolatinas na Sedes Sapientiae, localizada no terreno do colégio e foi a ex-professora de latim e português da classe secundária experimental, tendo atuado apenas um ano nas classes tradicionais (MINÉ, 2018). Entrevistas são reconstruções das imagens e representações do que foi vivido e o que se recorda são espaços que contém em si um tempo refreado (BOSI, 2012). Para isso, o presente ensaio afasta-se de uma perspectiva positivista da história e entra na Nova História, que oscila entre o vivido e o construído, o sofrido e o fabricado. Assim, o suporte da pesquisa estará na metodologia da história oral e na ponderação sobre o conceito de memória, pois o ato mnemônico fundamental é o comportamento narrativo e a memória é parcial, subjetiva e manipulável pelo interesse, afeto, desejo, censura (LE GOFF, 1996), pois ela está sempre em reelaboração e é seletiva. Por isso, quando se trata do uso da história oral não se busca por certezas, mas por dar voz as narrativas esquecidas; porque este uso vai além do que pode ser dito, ele abre caminho para o decurso ativo de produção de significações (ALBERTI, 2004).

Por fim, toda esta reflexão torna-se importante, pois as classes secundárias experimentais são exemplos de uma ruptura com a cultura escolar tradicional, rígida e arcaica do ensino secundário brasileiro, que podem ajudar a reinventar os anos finais do ensino fundamental e o ensino médio. De outra parte, também busca dar dizibilidade a uma experiência pedagógica inovadora que foi quase apagada pela história oficial. Desse modo, o texto está dividido em duas partes: a primeira tratará do grande espaço tradicional do colégio e da organização das dimensões espaço-temporais na "casinha", espaço dedicado a classe secundária experimental. Já a segunda parte versará sobre o ensino personalizado com foco nas fichas e seu uso inovador e nas avaliações conceituais qualitativas, além da face comunitária do ensino e o momento da partilha.

\section{Espaço e tempo transformadores}

Qualquer ofício humano utiliza-se de um espaço e não seria diferente com a atuação escolar. Então, ao entender que o espaço também é um agente educador e cheio de intenções socioculturais, enxerga-se a escola como um lugar marcado por subjetividades. $\mathrm{O}$ espaço educacional ocupado pela escola antes e durante a aplicação das classes secundárias experimentais era em grande parte tradicional e rígido. Desse modo, tem-se o espaço escolar das classes experimentais como uma quebra com o vigente ao utilizá-lo de maneira diferente na construção de um lugar de ensino inovador. Ao compreender a tomada de posse do espaço vivido como um agente conformador da personalidade e da mentalidade do indivíduo e dos grupos (FRAGO, 2001) e consequentemente da sociedade pode-se dizer que foi "sob a égide das classes secundárias experimentais que começou, [...], a funcionar em termos atuais o processo de responsabilidade própria, diversificação e autoafirmação da escola secundária brasileira" (CUNHA e ABREU, 1963, p. 92). 
Figura 1 - Fotografia do palacete, antes pertencido à família Uchoa e em 1907 sede do Colégio Des Oiseaux



Fonte: BATISTA, 2015.

Com a chegada das irmãs belgas de ascendência francesa da congregação de Nossa Senhora das Cônegas de Santo Agostinho ao Brasil em 1906 na intenção da fundação de um colégio, nasce, no ano seguinte, o Colégio das Cônegas de Santo Agostinho em São Paulo destinado ao público feminino. O colégio foi estabelecido em um palacete, como demonstra a Figura 1, no bairro da Consolação, próximo a Higienópolis, zona nobre de São Paulo. Neste contexto percebe-se a utilização do espaço do colégio católico como o lugar formador de excelência da elite paulista, ou seja, higienizador, tanto físico como moral, e privilegiado, onde essa organização espacial transmitiu através da sua materialidade um sistema de valores. Além disso, dentro do espaço escolar manteve-se uma cultura francesa viva para assemelhar-se com um autêntico colégio francês, pois, apesar das freiras serem belgas, a ascendência francesa falava mais alto na construção da identidade institucional. Tanto que, ele era apresentado como "uma filial do Colégio Notre-Dame Des Oiseaux de Paris, que atendia as famílias da antiga nobreza francesa e da grande burguesia parisiense", que o tornou conhecido como apenas Des Oiseaux (PEROSA, 2006, p.98).

Assim, o Colégio das Cônegas de Santo Agostinho serviu como um agregador de relações entre as famílias financeiramente poderosas da época e um segregador social, por manter distância espacial e social das camadas populares. A análise de como se deu a construção deste espaço escolar, tanto o físico, como o lugar educador por ele utilizado chega-se a máxima de que desde a fundação do Des Oiseaux tinha em si a consciência do que queria representar: uma elite homogênea, moralista, salubre, higienizadora e bem educada nos nobres moldes francês e católico; e do que ele deveria apropriar-se para conseguir fundamentar sua representação da época.

Em contrapartida, entende-se que toda pedagogia ativa, como é o caso da Pedagogia Personalizada e Comunitária, utilizada na classe experimental do colégio das Cônegas, faz um uso didático e ativo do espaço e seu entorno. De acordo com Pierre 
Faure (1993), um ensino personalizado e comunitário requer do espaço uma estrutura que permita aos alunos trabalharem em grupo ou em projetos pessoais. Para isso as salas devem estar propícias ao estudo, à documentação e ao trabalho, assim como seu mobiliário, que deve ser móvel, leve e simples, possuir estantes abertas para a organização e fácil manuseio dos materiais, dispor dos instrumentos de trabalho e uma biblioteca de fácil acesso. Ou seja, um espaço que ensina e incentiva a aprendizagem de forma autônoma, a pesquisa, o estudo, não um simples espaço para uso escolar, mas um lugar educador e responsável pela formação de pessoas, que se insere e interage com o seu entorno.

Figura 2 - Formatura do colegial (1965) no jardim lateral da casinha e suas grandes janelas



Fonte: Arquivo pessoal da ex-aluna Lia Mattos

A casinha, segundo a ex-professora Elza Miné (2018), foi o espaço exclusivo e demarcado para a construção desse lugar, onde a primeira turma do secundário experimental viveria sua experiência inovadora da PPC. O que foi perdido na mudança para o Colégio Madre Alix, que já não contava com um espaço exclusivo, misturando mais a cultura escolar institucionalizada e a experimental, pois dividiam o mesmo espaço comum, ficando a inovação restrita à sala de aula (MINÉ, 2018). A casinha, situada entre a Sedes Sapientae Faculdade de Ciência e Letras, o prédio principal do Des Oiaseaux e o bosque dos pinheiros, foi um espaço específico e privilegiado dentro do grande espaço utilizado pelo colégio. $\mathrm{O}$ espaço interno da casinha não era grande, possuía uma sala pequena, onde aconteciam as aulas expositivas quando necessárias, e uma sala, que dava para outra sala, onde estava o ambiente propício à pesquisa. As salas possuíam amplas janelas que davam para o jardim como demonstrado na Figura 2 da perspectiva externa, banheiros e uma pequena cozinha (MINÉ,2018).

O uso didático do espaço da casinha foi praticado de maneira semelhante ao prescrito por Pierre Faure (1993), ou seja, favorável as práticas personalizadas e 
comunitárias. A sala, que mais se assemelharia a uma sala tradicional, era o espaço onde acontecia a permanência e as aulas expositivas, mas ao mesmo tempo se constituía em um lugar totalmente diferente, pois existia liberdade de movimento. As carteiras, pequenas e móveis, podiam ser utilizadas ou não, sendo o chão uma possibilidade de assento e existia uma estante aberta para guardar os cadernos e itens pessoais e os alunos podiam se utilizar do espaço livremente (MINÉ, 2018). Na outra sala depois do arco era a que dispunha dos materiais de geografia, história, matemática, artes e possuía uma pequena biblioteca feita especialmente para a turma do experimental, mas que também podia frequentar a biblioteca que ficava no espaço do Colégio (MINÉ, 2018). Nessa descrição fica visível a descompartimentação horizontal sugerida por Faure (1993).

Por tanto, pode-se subentender que a primeira turma do experimental teve uma impressão forte e marcante da cultura escolar construída com a PPC, por ter tido um lugar educador propício para a experiência. Logo, ao olhar para a casinha, vê-se que ela carrega em si um produto de seu tempo, a década de 1950, que ansiava por renovação em um ambiente tradicional, salubre e rígido. Assim, o prédio do Colégio das Cônegas de Santo Agostinho carregava a expressão simbólica desses valores ainda dominantes da época. Então, ambos os espaços se constituíram como um lugar pelo suporte da memória coletiva (SCHMIDT, 1993) em suas identidades: uma tradicionalista e outra que se constituía como resistência.

Já o tempo escolar como um tempo institucional se coloca de maneira prescrita e uniforme, que tenta disciplinar, organizar, racionalizar e controlar externamente uma cultura escolar. Porém, esse tempo não é singular, ele existe em múltiplas facetas: estruturando os níveis, organizando o calendário escolar e os microssistemas temporais que dividem as disciplinas nas unidades de tempo estabelecidas. Assim, os tempos escolares ficam atrelados ao social, cultural, político e metodológico e não são neutros (FRAGO, 1998), logo, não agem de forma linear na construção da cultura escolar como se prescreve, pois, ao mesmo tempo que eles a moldam, também são moldados por ela. Assim, no olhar tradicional, o tempo terá essa função rígida, fragmentada e de imposição que é rompida nas pedagogias ativas pela possibilidade de uma flexibilidade e uma certa autonomia no controle pelos alunos do seu tempo de estudo, como ocorre na PPC.

A pedagogia fauriana prescreve uma personalização do tempo em respeito aos ritmos diferentes e a subjetividades dos alunos, na intenção de que ele perceba e organize seu tempo, transformando o modo de ensinar e de se relacionar com a aprendizagem, mas dentro dos propósitos metodológicos. Então, Faure (1993) propõe que o método seja aplicado no regime de semi-internato e que o dia se equilibre entre o trabalho mental (matutino) e corporal, artístico e manual (vespertino), pois o homem, a criança trabalha com todo o seu ser - corpo, alma e espírito; já os ciclos de aprendizagem são colocados de maneira a serem trabalhados quinzenalmente. Na classe secundária experimental do Des Oiseaux, as tarefas eram quinzenais, a avaliação mensal e o dia como o prescrito, tratava da atividade mental pela manhã, onde os alunos tinham o período de permanência e depois aulas expositivas, e a tarde eram as matérias como artes, educação física, que ocorria na área externa da casinha seguidas de outro período de permanência (MINÉ, 2018).

A permanência era um tempo colocado para que o aluno pudesse ler, pesquisar e resolver as tarefas do ciclo quinzenal propostas nas fichas de trabalho e os professores revezavam-se no posto de atender às necessidades das alunas para dúvidas e 
orientações, que tinha como local a sala principal da casinha. Porém, a permanência no fim do dia tinha como responsável o professor principal ${ }^{1}$ da turma e atividade era semelhante a um balanço do dia como relata a ex-professora:

Uma atividade que a gente fazia com elas, que queria discutir a manhã ou alguma coisa como é que tinha sido, elas sentavam no chão e a gente também, fazíamos um semicírculo. [...] e aí era um momento sagrado de atenção para discutir a sério. [...] E isso demorava, fazíamos uns exercícios de descontração [...], mas isso não estava assim prescrito! É a gente que foi inventando, mas funcionava muito bem (MINÉ, 2018, p.14).

Percebe-se um uso tático do tempo de permanência para um trabalho de organização em conjunto, que transcendia uma função apenas intelectual.

Assim, essa permanência final reverbera uma união dos dois momentos do dia mental e corporal - ao trabalhar um momento de discussão das dificuldades, impressões dos aprendizados e por propor práticas de relaxamento, concentração e trabalhar o emocional através do corporal. Esse tempo vivido no final do dia reflete a construção de uma cultura não prescrita e o momento que mais aproxima o conceito comunitário da PPC por conta da partilha e do momento de ser do grupo como um todo, diferente do primeiro momento de permanência que é mais individual, podendo ou não ter uma ação colaborativa. Pois, de acordo com a ex-professora o papel do trabalho em equipe não era muito enfatizado, mas existiam tarefas que exigiam que as alunas dividissem os afazeres entre elas para conclusão e apresentação do trabalho (MINÉ, 2018). Logo, tem-se nessa nova cultura escolar uma grande ruptura com a estruturação do tempo na escola tradicional, mas uma dificuldade em superar o individualismo das escolas tradicionais.

Essa ruptura sai da programação fragmentada do dia, da semana e mensal, que costumam ter as escolas tradicionais e coloca-se num programa quinzenal de resolução de atividades, que provocaram um novo ritmo à cultura escolar das classes secundárias experimentais. Afinal, de acordo com Faure (1993), deseja-se alunos dedicados, concentrados na execução das atividades, guiados pelo que foi proposto e organizado pelo professor, que eles pesquisem, documentem, reflitam, sejam autônomos, mas sujeitem-se ao controle, às prescrições, que partilhem e aprofundem, "preciso é fornecer-lhes tempo!'(FAURE, 1993, p. 67).

Com isso, fica claro no tempo escolar das classes secundárias experimentais a importância da mediação do professor no direcionamento do desenvolvimento da autonomia do aluno e da organização do seu tempo de estudo. Afinal, as atividades eram organizadas pelo professor através das fichas de trabalho, que tinham quinze dias para serem efetuadas, e orientadas caso o aluno não conseguisse se organizar de maneira satisfatória. Então, apesar de certa liberdade temporal na resolução das atividades, o professor continuava tendo um papel estrutural na construção da aprendizagem, sendo um ensino ativo, mas bem diretivo. Dessa forma, a ordem temporal unida a espacial são organizadoras da pesquisa do alunado e mantenedoras do método inovador da cultura escolar construída.

\section{A pesquisa como proposta de ensino autônomo e compartilhado}

\footnotetext{
${ }^{1}$ Um professor da equipe que ficava designado para ser o responsável pela turma, almoçava com eles, ajudava no que precisasse, discutia dúvidas e conduzia a permanência do final do dia (MINÉ, 2018).
} 
Depois de tratar do tempo e do espaço como instrumentos da construção do inovador ensino personalizado e comunitário, busca-se o entendimento da base dessa pedagogia: o ensino pela pesquisa através da construção autônoma (personalista) e compartilhada (comunitária) do conhecimento. Para desenvolver tal ensino, as proposições de Faure (1993) colocam em evidência a pedagogia por objetivos, que traz o uso das fichas; a criação de uma atmosfera de trabalho incentivadora, reflexiva e confiante; a proposta da autocorreção e autoinstrução; a mediação e incentivo docente como garantia de organização e aprendizagem integral; a interdisciplinaridade; a partilha como aspecto comunitário; a descompartimentação; a ação participativa dos pais; e, por fim, uma classe reduzida de alunos. Então, ao prescrever a Pedagogia Personalizada e Comunitária, Faure deixa clara a sua intenção de promover um ensino que desenvolva integralmente o aluno, que o estimule a pensar, a criar de forma autônoma e pessoal.

Desse modo, na experiência do colégio das Cônegas de Santo Agostinho com a classe secundária experimental, a grande inovação começa com o número de alunas que diminui de 40 na classe tradicional para 30 alunas na experimental. Essa mudança atrelada a restruturação do espaço e do tempo, torna propício o ambiente para a personalização prescrita por Faure, que na prática do colégio teve como sua principal base norteadora as fichas de trabalho. Segundo Schreiber (2016), a principal mudança da cultura escolar das classes secundárias experimentais do Colégio Santa Cruz, educandário católico, paulista e masculino, que também participou da experiência e dos cursos ministrado por Pierre Faure, foram essas fichas apropriadas do sistema de fichas do professor Robert Dottrens, do Instituto Jean Jaques Rousseau de Genebra. Assim, Dottrens (1974) propõe um educar que anteceda o instruir e seja pautado no respeito, na ciência, na responsabilidade advinda da personalização do ensino, na superação e progresso constante do aluno, trabalhando as dimensões a pessoal e a comunitária na formação do aluno, ideias que estão na construção de todo o ensino da Pedagogia Personalizada e Comunitária.

Como eram usadas essas fichas na classe secundária experimental do Des Oiseuax? Elas serviam como um roteiro de estudos, eram iguais para todas as alunas do mesmo nível, programadas pelos professores de cada disciplina com uma bibliografia de referência. As fichas de trabalho tratavam de um programa de estudo individual, onde dentro de uma quinzena as alunas organizavam suas atividades de pesquisa, leitura e escrita para a resolução das questões que constavam nas fichas. Além disso, existia uma orientação do professor com o intuito de garantir o desenvolvimento da atividade no prazo e de maneira satisfatória e, dessa maneira, as alunas reconheciam suas dificuldades e facilidades e aprendiam a administrarem o seu tempo de estudo (MINÉ, 2018). E era papel do professor dar ânimo e segurança para que os alunos seguissem no trabalho regular (FAURE, 1993).

A ideia de um ensino personalizado traz certa liberdade, que estava diretamente ligada a um poder de escolha, e mesmo que limitado era algo que quebrava fortemente com o ensino tradicional. Existiam essas fichas onde as atividades eram propostas, em que "eles tinham que fazer o trabalho de pesquisa individual, eles! Por isso é que [o trabalho] estava determinado nessas fichinhas" (MINÉ, 2018, p. 6). Neste caso, o fato de as alunas do Colégio das Cônegas de Santo Agostinho poderem criar um ritmo próprio, dentro da quinzena, de trabalho e de administrarem as fichas propostas pela equipe docente de acordo com seus pontos de vista, abria-se um espaço de liberdade pessoal que se distanciava do sistema de ensino tradicional, ou seja, trazia em si a 
máxima do "aprender fazendo", mas com responsabilidade, que era orientada pela mediação docente. Como lembra a ex-professora Elza Miné: "olha, eu acho que a grande inovação que ela (a experiência) trouxe foi uma responsabilização do aluno do seu próprio projeto de estudo" (MINÉ, 2018, p. 6) e isso trouxe toda uma reestruturação da cultura escolar da classe secundária experimental do colégio das Cônegas.

Essa noção de responsabilização do uso da liberdade prescrevia certo direcionamento e limite, que encontravam alicerce na mediação da professora e na execução das fichas propostas, como a recorda Miné (2018, p.6): "tinha uns horários assim em que o professor estava ali na sala à disposição e eles estavam estudando"; e se eles tinham dúvidas essas eram sanadas e muito bem orientadas; "o que foi muito formador para eles, é que eles sabiam o que tinham que fazer naquela quinzena, né? Que estava nas fichas para todo mundo", percebe-se a importância dada à descrição objetiva da atividade e a disponibilidade da orientação docente, além do tempo amplo para o sucesso do trabalho individual. Assim, a PPC e as classes secundárias experimentais, que dela se apropriaram, apesar de terem como proposta desconstruir o autoritarismo e a rigidez do ensino tradicional, não eram livres de normas, moldes e padrões, estes eram somente colocados de maneira mais flexíveis e mais pautados nas necessidades do aluno.

De acordo com De Gómes (1997) a PPC sempre integra liberdade com senso de responsabilidade, criatividade com propósito e rigor, ou seja, o aluno é um ser autônomo em construção e por isso deve aprender a ser livre, pois é seu direito, porém com responsabilidades, para isso deve ter uma meta, um objetivo e ser mediado em como usar de seus direitos corretamente. Nas classes secundárias experimentais esse objetivo, essa meta se traduzia na utilização das fichas de trabalho e na quinzena, que estabeleciam os objetivos a serem alcançados (os conhecimentos adquiridos pelo que foi proposto nas fichas) e a meta era cumpri-los em quinze dias. Afinal, "o trabalho personalizado é a base e o meio para uma formação pessoal sólida, para uma aprendizagem segura e durável e onde cada um orientado ao seu futuro, cresça e progrida de maneira contínua" (LE GALL, 1976, p.11, tradução livre) e se desenvolva integralmente. A garantia desse progresso está no professor, que ganha a função de facilitador do caminho que o estudante irá traçar e responsável pela programação das fichas, pois se

\footnotetext{
eles tinham dificuldade de se organizar, então tinham alunos que tinham dificuldades de fazer isso, então aqui entrava a função do professor. 'Você está dando muito pouco tempo para fazer essas tarefas, você tem que dar mais tempo, [...] eu acho que isso criou uma visão do tempo, uma visão da maneira de distribuir e ensinou essas crianças efetivamente a pesquisar (MINÉ, 2018, p. 6).
}

O uso da biblioteca é extremamente frisado pelo Pierre Faure, sendo o principal instrumento de trabalho do aluno pesquisador por compor uma variedade de livros para a busca e a pesquisa. No caso da casinha do Des Oiseaux, "não era uma biblioteca grande, porque tinham a biblioteca do colégio. [...] Mas a gente tinha um armário grande assim, de todos os livros que estaríamos usando para consulta, para toda aquela turma, então elas tinham ali tudo direitinho para elas" (MINÉ, 2018, p.15). Desse modo, um elemento prescrito tão imprescindível à PPC por tratar tanto do aparato base de um pesquisador como por trazer o cuidado com os objetos de uso coletivo, trabalhando assim a educação social (DE GOMÉS, 1997), e que conseguiu ser efetuado na prática. 
A intenção de Pierre Faure do progresso contínuo vem carregada da ideia de que a escola deve preparar os alunos para sua vida social. E é esse pensamento que dialoga com a face comunitária proposta na sua pedagogia, que se materializa nos momentos de partilha e convivência, que são permeados de experiências diversas que colocam os alunos em contato com situações de confronto, de autoanálise, de construção de sentido/respeito/conhecimento; e a partir disso, a escola também pode inculcar valores e normas (ESCOBAR, 1996). Assim, essa face aflora a sociabilidade e a integração, mas afasta-se do que seria a proposta de uma educação comunitária pautada na assistência social do entorno. Os momentos de partilha são então momentos de divisão do que foi conquistado por cada aluno no seu trabalho pessoal ou em equipe e desse modo todos se beneficiam dos conhecimentos uns dos outros.

Porém, não se vê na classe secundária experimental do Des Oiseaux o trabalho em equipe como algo que foi colocado em prática para o desenvolvimento da perspectiva comunitária, "não foi assim uma marca assim tão, tão marcante do, pelo menos eu não me lembro. Eu lembro assim de ver muito o desenvolvimento de cada uma delas" (MINÉ, 2018, p. 13), evidencia-se a força do trabalho pessoal na experiência pelo que ficou marcado na memória. Conforme Escobar (1996), o sentimento de comunidade dentro da perspectiva personalizada advém de uma das faces da normalização do trabalho, que se constrói com respeito mútuo, com senso de responsabilidade, com ajuda mútua, com acolhimento e aceitação. Através disso, instaura-se na classe uma pequena comunidade de alunos, ou seja, uma base comunitária, que poderia facilmente ser entendida como colaborativa e socializadora.

A interdisciplinaridade foi fortemente trabalhada, sendo reforçada nas reuniões semanais dos professores, na junção de disciplinas como história e geografia ou português e latim. A ex-professora Elza Miné (2018) relata que fazia comparações/relações entre o latim e o português e ensinava um pouco de história romana para não ficar muito cansativo, outro exemplo interessante foi quando no estudo das vogais ela levou para sala um aparelho fonador real conservado em formol para as alunas vivenciarem a origem biológica dos fonemas, além da lembrança da produção de um centro de interesse sobre a região nordeste. Atitudes que colocam em relevo o incentivo da pesquisa, da curiosidade, da criatividade e da busca por conhecimento.

A dimensão espiritual proposta por Faure (1993) na apropriação da experiência do Des Oiaseaux, resumiu-se as aulas semanais de religião, vivência das comemorações religiosas como a festa de Santo Agostinho e da presença constante da madre Isabel Sofia, grande liderança do movimento renovador no colégio, no dia-a-dia da turma, inclusive ela muitas vezes aparecia nos momentos de outras professoras e assistia, todas elas; "nós palpitávamos em tudo. Gostávamos" (MINÉ, 2018, p. 26)

Outra apropriação relevante nas classes secundárias experimentais foi a avaliação, que era conceitual, onde se buscava avaliar o aluno como um todo e não apenas uma nota em relação a um desempenho de uma atividade específica. Para organizá-la fazia-se um boletim mensal com os conceitos: muito bom, bom, insuficiente e sofrível e um comentário final sobre o desenvolvimento da aluna; isso era feito na reunião dos professores e escrito pelo professor principal da turma, mas não existia reprovação, as alunas que ficaram insuficientes faziam um reforço (MINÉ, 2018). Segundo Klein (1998), Faure defendia que o aluno não falha a um exame se este está bem proposto e programado, mas o sistema escolar sim falha em não se adaptar as necessidades do aluno. E, quando havia qualquer situação complicada, os pais eram solicitados para uma reunião (MINÉ, 2018), de modo que fica evidente a dimensão de 
diálogo entre os pais e a escola proposto por Faure (1993), e a participação ativa destes na transformação do ensino.

Em suma, o sucesso da perspectiva personalizada está na organização e preparo docente da orientação do aluno para que este aprenda pesquisando. Sucesso este que foi mediado pelas fichas quinzenais, pelos materiais disponíveis, pela intervenção docente e pela participação dos pais no projeto educativos de suas filhas.

\section{CONSIDERAÇÕES FINAIS}

A Pedagogia Personalizada e Comunitária chegou ao Brasil com Pierre Faure, seu criado, que preencheu o anseio renovador dos educandários católicos particulares com o seu interesse na construção das classes secundárias experimentais. $\mathrm{O}$ foco dessa pesquisa foi o educandário feminino das freiras belgas de ascendência francesa, Colégio das Cônegas de Santo Agostinho, que se apropriou da PPC e através das transformações espaço-temporais e do inovador ensino pela pesquisa, que construiu uma nova cultura escolar dentro de um educandária marcado pela viés tradicional franco-europeu. Essa experiência visava a realização de uma inovação no ensino secundário que crescia em todo o contexto educacional da década de 1950, tanto em sistemas públicos de ensino como em redes e colégios privados, particularmente nos colégios de religiosos católicos.

Através da leitura das memórias da ex-professora de português e latim, Elza Assunção Miné, foi construído um paralelo da análise crítica entre o que foi prescrito pela proposta pedagógica faureana e o que foi praticado na experiência da classe secundária experimental realizada no espaço da casinha do Des Oiaseaux, entre 1959 a 1962, transformando a cultura escolar católica tradicional. Nesta investigação, deve-se considerar a complexidade de se trabalhar sobre lembranças de um espaço que contém tempos comprimidos e que está permeado de subjetividades, descontinuidades e incertezas. No entanto, quando conectadas a um contexto histórico e feita as conexões necessárias com as fontes sobre a Pedagogia Personalizada e Comunitária, tem-se um ensaio complexo sobre uma experiência que existiu no prescrito e no praticado e que foi vivida criativamente pelos sujeitos envolvidos.

Percebe-se que na rememoração da professora, a apropriação se deu de maneira marcante no viés personalizado, que incentivava fortemente o ensino pela pesquisa de maneira autônoma, através principalmente do uso das fichas de trabalho, da interdisciplinaridade e da transformação do espaço para um lugar de ensino inovador e de certa flexibilização e controle do tempo pelo próprio aluno. Estas mudanças no cotidiano escolar transformaram os sujeitos que vivenciaram a experiência pedagógica inovadora na casinha como construíram uma cultura escolar na classe secundária experimental. Que trouxeram para uma época em que o ensino tradicional imperava de forma autoritária, rígida e quantitativa uma grande renovação, que merece rememorada, que reverberou no Colégio das Cônegas de Santo Agostinho até o fim de 1968, passando por muitas mudanças até seu fim.

Por tanto, há muito o que se aprender com a classes secundárias experimentais no Brasil e a PPC, que são pouco discutidas na história da educação, mas que merecem ser rememoradas para ampliar o repertório pedagógico brasileiro. Pois, "os espaços ocupados pelas classes secundárias experimentais representaram do ponto de vista da cultura escolar, novos usos e finalidades da escola" (SCHREIBER, 2016, p. 70). Assim, 
tanto a pedagogia faureana como as classes secundárias experimentais no Colégio das Cônegas de Santa Agostinho e em outros educandários católicos apresentam ideias e experiências que podem contribuir para a dinamização dos anos finais do ensino fundamental e do ensino médio na atualidade.

\section{REFERENCIAS}

ALBERTI, Verena. Ouvir contar: textos em história oral/ Verena Alberti. Rio de Janeiro: Editora FGV. 196p. 2004.

BATISTA, Liz. Era uma vez em SP... Colégio Des Oiseaux. O Estado de S. Paulo. São Paulo. 29 maio. 2015. Disponível em: < https://acervo.estadao.com.br/noticias/acervo,era-uma-vez-em-sp-colegio-desoiseaux, 11116,0.htm?fbclid=IwAR1B_VD1dO25bpwc69bHSjhgRqijIkc5qfyk7qaVj8z Amerz6D6g7BKHgCM>. Acesso: 04/06/2019.

BOSI, Ecléa. Memória e sociedade: Lembrança de Velhos. $17^{\mathrm{a}}$ ed. São Paulo: Companhia das Letras, 2012.

CUNHA, Nádia; ABREU, Jayme. Classes Secundárias Experimentais - Balanço de uma experiência. Revista Brasileira de Estudos Pedagógicos. v. XL, n. 91, p. 90-151, jul.-set., 1963. Rio de Janeiro.

DALLABRIDA, Norberto. Circulação e apropriação da pedagogia personalizada e comunitária no Brasil (1959-1969). Educação Unisinos. v. 22. n. 3. jul/set. 2018. p. 297-304.

- Circuitos e usos de modelos pedagógicos renovadores no ensino secundário brasileiro na década de 1950. História da Educação. Porto Alegre. v. 22, n. 55. maio/ago. 2018. p. 101-115.

As classes secundárias experimentais: uma tradição escolar (quase) esquecida. Revista Brasileira de História da Educação, v. 17, n. 3 [46], p. 213-234. 2017.

DE GOMÉS, Maria Nieves Pereira. Educação personalizada: um projeto pedagógico em Pierre Faure/ Tradução de Laureani Pelegrin. Florianópolis: EDUSC, 1997.

DOTTRENS, Robert. Educar e instruir I. São Paulo: Editora Estampa, 1974. 
ESCOBAR, Alvaro Vélez. Prática da educação personalizada. Tradução Fabio Duarte Joly. São Paulo: Loyola, 1996.

FAURE, Pierre. Ensino personalizado e comunitário. São Paulo: Loyola, 1993.

JULIA, Dominique. A cultura escolar como objeto histórico. Revista Brasileira de História da Educação. Campinas, n. 1, p. 9-43. 2001.

KLEIN, Luiz Fernando. Educação personalizada - Desafios e Perspectivas. São Paulo: Loyola, 1998.

LE GALL, Monique. ¿Por qué y cómo una pedagogía personalizada?. Revista de Educación. Edita: Servicio de Publicaciones del MEC. Ciudad Universitaria, Madrid-3 (España). n. 247. nov/dez. 1976. p. 5-205.

MINÉ, Elza Assunção. Entrevista concedida a Norberto Dallabrida. Florianópolis, 17.jul. 2018.

PEROSA, Graziela Serroni. Três escolas para meninas. 2005. Tese (Doutorado em Educação) - Universidade Estadual de Campinas, Campinas, 2005.

ROCKWELL, Elsie. La apropriación, um proceso entre muchos que ocurren em ámbitos escolares. Memoria, conocimiento y utopía. Anuario de la Sociedad Mexicana de Historia de la Educación. Ediciones Pomares, S. A. n1. Enero 2004 - Mayo 2005.

SCHMIDT, Maria Luisa Sandoval; MAHFOUD, Miguel. Halbwachs: memória coletiva e experiência. Psicol. USP [online]. 1993, vol.4, n.1-2, pp. 285-298. ISSN 1678-5177.

SCHREIBER, Stefanie. Cultura escolar no curso ginasial experimental do colégio Santa Cruz. 2016. 74f. Trabalho de Conclusão de Curso - Universidade do Estado de Santa Catarina. Florianópolis, 2016.

VIEIRA, Letícia; CHIOZZINI, Daniel Ferraz. Luis Contier como catalisador de redes: classes experimentais e renovação do ensino secundário em São Paulo nas décadas de 1950 e 1960. História da Educação. Porto Alegre. v. 22, n. 55. maio/ago. 2018. p. 6180. 
VIÑAO-FRAGO, Antônio (1943). Currículo, espaço e subjetividade: a arquitetura como programa/ Antônio Viñao Frago e Agustín Escolano. Tradução: Alfredo VeigaNeto. 2 ed. Rio de Janeiro: DP\&A, 2001.

Antônio. Tiempos escolares, tiempos sociales. Barcelona: Editorial Ariel Practicum, 1998b.

Recebido em: 10/11/2018

Aprovado em: 15/01/2019 